\title{
Biomimetic and sustainable design: a virtuous relationship
}

\author{
M. Stoppa \\ School of Architecture and Design, Edoardo Vittoria, \\ Camerino University, Italy
}

\begin{abstract}
We have achieved a stage where anthropic action has jeopardized the stock of natural capital to be left to future generations and where the use of green technology will not suffice to revert the current trends; it is necessary to undertake drastic innovations requiring the implementation of various strategies for changing our lifestyles and the entire economic and socio-cultural complex upon which the current production, use and consumption system is based on. This paper examines the need to strengthen the current conceptual and methodological-operative tools of eco-design by using the complex qualities of natural systems, that is the biological principles/functions that can be taken as guidelines to increase the effectiveness of the eco-design criteria with a view to provide the design culture with fresh bio-inspired conceptual and methodological-operative tools to obtain genuinely sustainable results. The theory of complexity, the theory of systems and the emerging technologies have supported the recent scientific findings on biological systems, based on the principle of "minimum inventory/maximum diversity"; they highlight and prove that biological systems, by means of their complex qualities, are governed by strategies/functions such as: self-organization, adaptability, feedback, redundancy, multifunctionality and resilience, which have enabled them to survive and evolve. The methodological-operative framework and the bioinspired guidelines, as a tool for sustainable design, are defined by analysing sustainability concepts (eco-efficiency, effectiveness, sufficiency and regeneration), the function of organisms and of the various natural analogical and omological levels. According to statistical data provided in 2002 by the Design Council of London, $80 \%$ of the environmental impact generated by products/services/infrastructures is determined at planning stage. Hence, the need
\end{abstract}


to examine and implement bio-inspired strategies/functions since the early designing steps. Implementing the current eco-design tools with bio-inspired concepts may lead to drastic innovations of the current production, use and consumption system.

Keywords: sustainable design, bio-ispired design approach, biomimetic guidelines.

\section{Introduction}

Since the late 80 s environmental issues - related to the "unsustainability" of the current life, production, consumption styles, the exploitation of environmental and energy resources, pollution and climate change - have come to the fore in the economic and political debate of the international community, giving rise to a considerable awareness campaign which involved institutions, companies and consumers. The idea of sustainable development, supported by various conceptual and methodological-operative tools of eco-design, or rather, designoriented from principles of environmental sustainability, was defined against this backdrop. However, various studies and research which took place over the last decade have revealed that the efforts made for creating the eco-design tools have not yielded the expected results. The researches on the "effect rebound" prove, by way of an example, how the eco-design conceptual and methodologicaloperative tools have not provided a practical solution [1]. Therefore, eco-design requires to strengthen/regenerate its conceptual and methodological-operative tools by adopting a more radical approach in order to tackle the current environmental challenges and help achieving the necessary sustainability objectives (, that is a swift and dramatic reduction in the current consumption of environmental resources). For several decades various researchers have highlighted the importance of adapting our lifestyle to the rhythms of nature under all respects [2-5].

In fact, the recent discussion on high technologies and the research of Earth Care Design promote the reorientation of technology on the principles of nature, through the scenario biomimetic. Therefore bio-inspired design allows us to approach the logic and principles of natural systems. In this respect Buckminster Fuller maintained: "We do not have to confine ourselves to imitate nature, rather we must try to identify the principles upon which it is based". Nature as a designer has a 3.8 billion year experience and evolution (trial and error) at the disposal of the culture of design as an enormous heritage of efficient planning solutions to draw inspiration from. Indeed "the main aspect characterising all living creatures certainly is the principle of minimum effort, maximum result, that is, using the least quantity of energy for one's own activities to guarantee the highest performances for the 'continuation of the species"' [2], a shared objective of eco-design also for Papanek [6]. Nature can be regarded as a very efficient design context as is marked by a number of characteristics, that is, both the need to apply its principles and models within a system characterised by environmental, matter, energetic and temporal ties, and the need to optimize energy resources with a view to guarantee the continuation of the species and the 
preservation of the optimal balance for the ecosystem [7]. However, man has always tried to imitate or draw inspiration from nature to improve his own artefacts, "but as of late we have witnessed an ability to examine and understand reality on the one hand, even getting to a nanometric level, and, on the other the ability to produce artefacts on the same highly reduced scale" [7]. Therefore, the guidelines and principles for designing sustainable and bio-inspired artefacts emulating the natural complex systems will be determined by the structuring/layout of the framework of methodological and operative references, as a support tool for sustainable and bio-inspired design. The reference framework includes the identification of: the concepts of weak and strong sustainability; the abstract principles and models of nature related to various bioinspired approaches, the identification of several abstraction levels of the natural models and the identification of the complex qualities/characteristics of the natural systems.

\section{Complexity of natural systems}

The research performed by Ilya Prigogine on adaptive complex systems have shown that the living systems characterised by a high number and variety of elements which are not connected in linear fashion attempt to adapt their characteristics to the modifications under way in the environment [8]. This is to maximise their possibilities of survival and occurs owing to a correct and successful processing of feedback and internal organisation, by means of potentially successful structures and processes taking place in the natural selection which enables them to evolve further. Kevin Kelly maintains that "the world we have created has become so complicated that we now need to address ourselves to nature to learn how to preserve its smooth running" [9]. Kelly defines the artefacts of the future neo-bio-logical civilization (born from the merging of technology and biology) as techno-biological systems: intelligent, almost organic, autonomous and adaptive artefacts increasingly similar to living beings on which man is bound to lose his grip. "The realm of what is borneverything natural - and the realm of the product - everything built - are becoming one single thing. Machines are becoming biological, what is biological is becoming mechanized. [...] Basically, the more we make our built environment mechanic, the more it will become biological, if it wants to keep on working" [9]. If, up until now, nature was regarded only as a resource of matter and energy, now, thanks to new knowledge and techniques it is possible to examine and know thoroughly the structures, processes, logic, and the way nature works and produce artefacts that mimic or integrate nature to optimize performances. Thanks to the theory of complexity, the theory of systems and the emerging technologies it was possible to understand the logic of "Bios", particularly of the biological systems which, as Langella explains, do not necessarily work in an "exact" manner; rather it is their sheer complexity which enables them to survive. The studies on the complex qualities carried out by Ilya Prigogine, Henri Atlan, Edgar Morin, Heinz von Foerster and Jean Pierre Dupuy have highlighted that biological systems survive and evolve thanks to their 
complex qualities [8]. Therefore, resilience, redundancy, adaptability and selforganization, characteristics that enable organisms to evolve and live in harmony with the biosphere, if applied to bio-inspired and sustainable artefacts, might provide environmental benefits throughout all the phases of a product life-cycle.

\subsection{Resilience}

Resilience is the ability of a system to endure disturbances without losing its balance. It is the feature that mostly differentiates complex systems (very resilient) from complicated ones (fragile, slightly resilient). "The resilience of an ecosystem lies in its ability to undergo an action of disturbance without irreversibly abandoning its balance. This concept, extended to the entire planet, brings in the idea that the natural system on which human activity is based has limits in terms of resilience that, when overcome, irreversible degradation phenomena set in" [10].

\subsection{Redundancy}

Redundancy is what enables resilience to be formed; it consists in the presence of further parts, repeated and apparently useless but, actually, each part is indispensable for the functioning of the whole system. Biological systems, according to Langella, have a quality defined "redundancy", which enables them to survive even the most unexpected and dangerous events, replying to them by using apparently "superfluous" elements or characteristics, whose existence finds its explanation only when the need arises.

\subsection{Adaptation}

Adaptation or adaptive capacity is the speed with which a complex system regains its state of balance after losing it. To guarantee their evolution, biological systems have developed a high adaptive capacity, which consists in the possibility to modify functions and structures as a result of the changes in the conditions of life and the environment. However, it is necessary to differentiate adaptive events leading to physiological and morphological reversible changes that cannot be transmitted in a hereditary way from adaptive events occuring as a result of natural selection, generating genetically transmitted features (i.e. An anatomic structure, a physiological process or a behaviour) that aim at increasing the survival likelihood of individuals provided with them; each feature can therefore be traced back to a specific adaptive value held in a specific environment. Another interpretation of the term adaptation is pre-adaptation, meant as the ability of a feature to facilitate the adaptation of a biological system even in a new and different environment from which it evolved. Terrestrial vertebrates, for example, originated from ancestral fish preadapted to terra firma; although their four side flippers were typically water organs, they were made in such a way that enables them to perform a few functions even in a subaerial environment [11]. Therefore the adaptability of the new sustainable and bioinspired artefacts can be meant as the ability to modify their characteristics as the 
external conditions vary; it could therefore be translated into multifunctionality or performance flexibility. "In this way it is possible to extend the useful life of a product by a lot. Design products must therefore adapt and update to the changing technological scenario, the economic climate and the users' demands. The objects that have been planned and produced to be flexible, modular and reconfigurable, both from the point of view of performances, dimensions and esthetics, are bound to last longer and, as a consequence, be used longer, thus obtaining a considerable environmental advantage connected with a saving lasting longer than the material and energy resources necessary to their maintenance or replacement" [12].

\subsection{Self-organization}

Self-organization is an emerging property of the complex systems and only depends on the local interactions between environmental inputs and the single elements of a system (the cells in an organism, the individuals of a social system, or simply mathematical entities) that give rise to organized dynamic structures (bottom-up) on the basis of their mutual interactions, without the need for a central project. A sound example can be found in morphogenesis, where cells proliferate and specialize starting from a single fertilized cell. The laws governing the evolution of the system as we had it cannot be traced back to the single elements that make it up; instead, they derive from the interaction among elements and are typical of the system as a whole [11].

The theorists of complexity maintain that self-organization is one of the most important evolutionary principles which materializes in the ability to generate potentially successful structures and processes, thus guaranteeing evolution. The systems that are able to be self-organized spontaneously increase their possibilities to evolve further. Self-organized characteristics are also those which are easier to remodel, and therefore are more flexible. To survive the changing of internal and external conditions, organisms tend to modify themselves and evolve in time by becoming self-organized so as to use both environmental disturbances to their own benefit and their own resource in the most efficient way [12]. Although the concept of self-organization has been applied to several disciplines, transferring the concepts of self-organization to the design of sustainable and bio-inspired artefacts is currently one of the main objectives for the production of sustainable and bio-inspired artefacts, especially with regard to energy saving. Indeed "The current context shows as energy saving will very likely be considered among the mains reasons of concern for the designer of the future. He will have to deal, on the one hand, with the reduction in the reserves of raw materials which have so far been regarded as fundamental for the current production systems, but bound to be increasingly scarce (see oil, aluminum and copper to name a few), and, on the other, the increase in the users who aspire to and reach conditions of affluence, never as today closely connected with the consumption of matter and energy" [7]. The emerging technologies and newlyacquired knowledge, however, make it possible to achieve results, although sometimes still of an experimental nature, which are useful for producing new bio-inspired and sustainable artefacts. This highlights to what extent the relation 
between nature and technologies is increasingly becoming closer with a view to make new "techno-biological" products. This aspect underlines the shift from a sheer emulation relationship with nature to one of integration with it, which will enable artefacts able to self-organize, self-repair, self-assemble and self-adapt to be produced. "With regard to design the level of development achieved in the various fields of scientific research enables, thanks to increasingly faster processes of technological transfer, to produce so complex artefacts as to resemble biological systems more and more. [....] Hybrid artefacts, halfway through nature and artifice. Structures and objects which are part of a technobiological universe, where artificial matter "takes shape", grows, evolves and changes into something else; where the systems are able to self-repair and selforganize as much as living organisms" [13].

\title{
3 Biomimicry and abstraction and emulation levels as methodological tools
}

\begin{abstract}
"Biomimetics (which we here mean to be synonymous with 'biomimesis', 'biomimicry', 'bionics', 'biognosis', 'biologically inspired design' and similar words and phrases implying copying or adaptation or derivation from biology) is thus a relatively young study embracing the practical use of mechanisms and functions of biological science in engineering, design, chemistry, electronics, and so on" [14]. For this, the several disciplines need a conceptual tool of abstraction that allows them to correctly identify the functional level to be extracted and the degree of imitation.

Several bio-inspired approaches have outlined the use of abstraction levels of natural models to facilitate comprehension of natural systems, for design purposes. These abstraction levels are: the analogical levels, identified by Carla Langella [8] and the homological levels by the Institute of Biomimetics [2]. Abstraction levels are useful for drawing from nature the various degrees of biomimetic imitation (micro, intermediate and macro) on the basis of the different functional levels [16].
\end{abstract}

\subsection{Analogical levels as methodological tool of emulation or integration}

P. Steadman believes that analogy is a resemblance of structures arising from an identity of an existing function, "Analogous, a part or an organ of an animal having the same function of the part or organ of another animal" [15]; an example is that of the wings of insects and birds. The analogical levels identified by Langella [8] are:

- Architectural level: the analogy refers to structures, beehives, holes, cobwebs, built by living organisms;

- Morphological-structural level: here the morphology of the bio-structures (cells, bones, biological tissues, mussels' shells) is imitated to obtain structures and materials with specific performances; 
- Biochemical level: this level sees the transferring of biochemical mechanisms observed in biological systems as camouflage mechanisms, the luminescence effect of fireflies, the cholorophyll photosynthesis;

- The level of the functioning logic: what is imitated is the logic underlying biological systems as the anti-friction function of the sharks' skin, the thermoregulation mechanisms of animals (penguins and bears) in extreme conditions and growth processes as in teeth, bones and horns;

- Behavioural level: it refers to the transferring of behavioural patterns, as the reactive or protective one of cell membranes used in the production of new materials and structures for filters and separating devices;

- Organizational level that is the priority aspect imitated from nature: this is the highest abstraction stage and consists in transferring organizational strategies typical of biological systems as redundancy, self-adaptation, autonomy, selforganization.

\subsection{Homological levels as methodological tool of abstraction}

For Steadman, homology is a resemblance in the body layout of organs, "Homologous, the same organ in different animals having each variety of shape and function" [15]. Homologous organs develop from corresponding embryonic parts; for example the arm in man is homologous to the forepaw in quadrupeds. On the basis of the sustainability level, Benyus and Baumeister identify and classify three homological levels, shape, process and system, with a "superficial" and "deep" approach to biomimicry [16]. This classification is described "in a progression from a first level (shallow), where the natural shape is mimicked, through an intermediate level where the natural processes are mimicked, up to a third level (deep) where imitation relates to the ecosystems. "Micro: lowcomplexity, form and function inspired by nature, shallow biomimicry; Intermediate: intermediate complexity, process inspired by nature; Macro: High-complexity, system inspired by nature, deep biomimicry" [16]. The analogical and homological abstraction levels can be used to identify both the degree of imitation (micro-intermediate-macro) through the homological level, and the function to be mimicked through the analogical level.

\section{From weak sustainability to strong sustainability: strategies for sustainable design}

Although this concept has undergone a number of changes and implementations, there are two important notions arising from the various definitions: the concept of "weak sustainability" and "strong sustainability" which regard the "natural capital", the "concept of wellbeing" and the "responsibility towards future generations" in a different way. The concept of "weak sustainability" hinges on the material wellbeing of man; this acknowledges the need to preserve "the stock of the overall capital" in time, which is given by the sum of the natural resources (natural capital) and artificial ones (produced capital). The champions of this line of thinking maintain that it is sufficient to leave future generations with a 
quantity of material good not lower than the current one, since the natural capital - or at least part of it - lost as a result of the anthropic activities can be suitably replaced by the artificial capital thanks to technological solutions. The concept of "strong sustainability", on the other hand, is based on the wellbeing between the generations, which can only be achieved through the preservation of the "natural capital" in time and cannot be replaced with the "artificial capital" $[17,18]$. It is therefore necessary to keep and preserve the stock of natural resources in time for future generations, taking into account not only the quantity of the "natural capital" but also its quality. Those who support strong sustainability believe that that the natural capital cannot be replaced by the artificial capital, therefore they underline the need to preserve the environment and the natural services fully. Basically, they want to preserve the environment's potential to produce resources and be self-generating, extending responsibilities to other living species and granting future generations the possibility to choose how to use the natural heritage and how to build and reach their wellbeing. Embracing the concept of strong sustainability in a serious manner involves understanding the conceptual tools, which have marked the environmental sustainability so far and the new ones emulated by nature, leading to a fresh sustainability scenario.

\subsection{Eco-efficiency}

The concept of eco-efficiency refers to a vision involving a lower use of resources and a lower output of waste and polluting agents for the production of goods and services. That is why the eco-efficient use of resources was, in the past, a pivotal concept for environmental design. 1993 saw the WBCSD (World Business Council for Sustainable Development) defining the concept of ecoefficiency: "Eco-efficiency indicates the ability to provide cost-effective products and services meeting the requirements of man and improving the quality of life while progressively reducing the environmental impact and the consumption of resources throughout the entire life-cycle at a level which is at least in line with the planet's carrying capacity" [17]. The latter statements in the description of the concept of eco-efficiency by WBCSD are important to understand how ecoefficiency is an anthropocentric concept, as it attempts to reduce the environmental impact of products, but it is not an adequate strategy to tackle the current environmental challenges effectively, because it does not safeguard the natural capital pre-emptively. The concepts of strong sustainability, on the other hand, borrow the functions and principles of nature (closed cycles, cooperation, localization, regeneration) and are targeted towards the safeguard, restoration and regeneration of the natural capital. "Eco-efficiency is apparently a praiseworthy concept, even a noble one, but it is not a successful strategy in the long run because it does not go deep enough, if not for the fact that it works within the same system causing the problem, and is confined to slow it with moral prohibitions and sanctions. It is nothing more than a delusion of change. However, relying on eco-efficiency to save the environment would trigger the opposite effect; it would enable industries to consume everything without any problem and seamlessly" [3]. 


\subsection{Concepts for strong sustainability emulated by nature}

Although the concept of eco-efficiency has had a partial success, despite several products were redesigned, and their eco-efficiency was highly improved by making all industrial products "lighter" (in the sense that their environmental impact was reduced - the ecological footprint - due to their individual existence), data unfortunately reveal that the total consumption of natural resources has continued to grow. This is particularly due to the increase in the request for products. Such contradiction, between expectations and results, of the concept of eco-efficiency is one of the puzzling aspects, during the learning process, we came up against. They have been defined as the boomerang effect (also termed as rebound effect). Choices regarded as favourable for the environment turned out to be quite the reverse as a result of an intricate series of events [1-10]. To tackle these issues, that is the rebound effect and the impractical nature of the current environmental strategies, various researchers maintain that it is necessary to identify, adopt or add other strategies, apart from those related to eco-efficiency (incremental innovations), that dramatically change the concepts/strategies for sustainability by adopting drastic innovations involving the socio-cultural sphere. Therefore the concepts of eco-effectiveness, sufficiency-reparation and regeneration as concept for a strong sustainability will be examined.

\subsubsection{Eco-effectiveness}

An important contribution to understand the concept/strategies of ecoeffectiveness was outlined by the movement "from cradle to cradle" by McDonough and Braungart, where the concept of "rejection" is abolished. Artefacts are regarded as elements designed to reappear in the metabolism of technical or natural materials that is the product that was no longer to be used and was earlier regarded as waste to be disposed of; now becomes a resource for a new technical or natural system. The concept of eco-effectiveness is also shared by Gunter Pauli who defines eco-effectiveness as a conceptual and operative tool to obtain "Zero-Emission Systems" where the concept of rejection is left behind: basically, all the outputs in a process are reintegrated as inputs in other processes [20], as happens in nature [21]. A radical change in the concept of eco-design that McDonough and Braungart define as a shift from ecoefficiency to eco-effectiveness. takes place [3]. In this respect, the authors maintain that: "Eco-efficiency simply works to the extent to which it makes the old system slightly less destructive. In a number of cases it can also be dangerous because its mechanisms are more subtle and long-term. An ecosystem could actually be again sound and intact following a short-lived collapse leaving a few niches untouched, rather than a slow, deliberate and efficient destruction of everything" [3]. If the objective of eco-efficiency consists in eliminating, or better, limiting the damages arising from processes and products that have not been thought by taking into account their environmental impact, ecoeffectiveness wishes to be a new design approach drawing inspiration from natural systems. 
Few Principles of eco-efficiency: using waste as a resource; optimizing the system rather than maximizing the components; adapting shape to function according to morphologies which save materials and energy.

\subsubsection{Sufficiency and restoration}

The concepts of sufficiency and restoration both indicate the possibility for man to keep on producing, using and consuming while respecting the resilience of nature, using available goods and resources [22], and resuming "the capability of local natural systems to a healthy state of self-organization" [21].

Whereas for Tackara [29], the concept of restoration, referred to economy, indicates a socio-economic organization that works with goods already possessed or that are available at the moment, keeping a high level of resilience with a view to put forward ways of thriving without overloading the natural and social systems. The concepts of restoration defined, as a concept of sufficiency, by Andrea Segrè [23] leads us to question and abandon the current principles of organization of economic activities focused on the uncontrolled exploitation of environmental resources. Segrè believes that undertaking the avenue of sufficiency means "rejecting the pragmatism of those who consider environmental resources as "given" and believe that the human and natural capital are interchangeable [....] The word sufficiency, instead, refers to a simple and intuitive concept: once the quantity of the consumption, which is regarded as optimal, of a good is exceeded, the said consumption becomes excessive [23]". Segrè identifies in the "sufficient society" the point of arrival where the concept of wellbeing is not determined by quantity, but by quality and where "more does not amount to better" and "enough is not too much" [23]. Sufficiency and restoration reduce the propensity to waste which characterises the current consumption model, not only typical of the Western world, thus integrating it with the idea of degrowth whose purpose is to rediscover values such as sobriety, simplicity and frugality [18-23].

Few Principles of sufficiency and restoration: producing only the necessary; zero waste production; using local resources; encouraging pressure and local temperature processes.

\subsubsection{Regeneration}

One last concept that might strengthen the shift from weak to strong sustainability is regeneration. This word derives from the Latin "regenerati-onis and indicates the action of regenerating and being regenerated. In biology one of the meanings of the term refers to a regular renewal implemented during the normal life cycle of an organism. The word "regeneration or regenerating" refers to those processes that have the ability to recover, renew or revitalize one's own physical state, energy and material sources, as much as occurs in nature. This concept finds its basis in regenerative agriculture and permaculture, and was resumed and worked out in architecture by John T. Lyle with the "regenerative design" whose objective is to requalify and revitalize the natural systems with a view to preserve the coevolution of the human and biological species [24]. With reference to the culture of design, an interesting/important contribution is that by Manzini E., who, in a number of essays, highlights the need/importance, on the 
part of the designers, to propose and materialize "low-intensity matter and energy solutions with a high regenerative potential", that is put forward low environmental impact solutions able to regenerate the quality of the context (environmental, social, cultural and technological) within which they will be framed [1].

Few Principles of Regeneration: building from bottom up, according structural hierarchies in modular fashion and without gaps; regenerating resources; encouraging self-assembling processes; supporting symbiotic relationships, mutualism and cooperation for the regeneration of the quality of their habitats.

\section{A virtuous relationship between biomimetic and sustainable design}

Kevin Kelly maintains that when the association between nature and product will be complete, our products will be learning, adapting, healing by themselves and evolving [9].

The strategies analyzed above are the main components of the metodologicaloperative framework, useful to define the quality of new sustainable and bioinspired artefacts. These artifacts:

- Apart from not jeopardising the resilience of the biosphere because they increasingly resemble biological systems, must be designed to meet the feedback of the external environment, that is endure disturbances without losing their balance with a view to evolve and obtain a functional and performance advantage by optimizing energy.

- Must be designed taking into account redundancy in order to tackle external disturbances. Redundancy can be structural or morphological, as for example the geometric redundancy in natural structures (i.e. the hierarchical structure of natural materials such as the abalone shell, wood, bone or cellular tissues and fractal structures). This enables biological systems to respond immediately to "unexpected events" from the external environment, thus increasing the resilience of the system of external disturbances.

- Must be able to reprocess the external environmental feedback in a positive way so as to achieve a better performance and functional adaptation and increase the life cycle of a product, thus resulting in a remarkable environmental advantage.

To make new bio-inspired and sustainable artefacts it is therefore necessary both to increasingly use the logic or organization with which nature generates its own organisms to mimic nature, (used, for example, in processing natural algorithms for computational design or $3 \mathrm{D}$ printers resorting to the bottom-up process), and the use of natural chemical processes to integrate nature, enabling, apart from the generation/production and maintenance of the structure of the new techno-biological artefacts, even their smooth running (for example the photosynthesis of green algae or moss to produce electric power). Emulating or integrating the characteristics of the complex systems might lead to a considerable energy saving (energy and matter) throughout the life cycle. 
"Nature has up to now given all of itself to mankind. First we have taken the resources at hand such as food, natural fibres and shelters. Then we have learnt to extract raw materials from the biosphere to create new synthetic materials. Now Bios is also giving us its mind - we are also taking its logic" [9].

\section{Conclusions}

To resolve the complexity of the current environmental, economic and social problem, the development of clean technologies and of more sustainable processes and products or of business environmental strategies will not suffice; it is instead necessary to pursue radical and non incremental innovations requiring a drastic change in the current production and consumption system, in the economic development model and in our lifestyles [5-19]. Tackling the current environmental challenges will require strengthening the current conceptual and methodological tools of sustainable design (eco-design) with new concepts, models, principles and qualities which are already part of the natural complex systems. This paper gathers and presents a selection of design biomimetic principles and guidelines that are increasingly being adopted and consolidated, especially in a number of bio-inspired design fields, as effective support tools for a bio-inspired approach aiming at developing bio-inspired and sustainable artefacts. It is a series of planning (conceptual) indications that, along with the methodological-procedural structure defined by the various concepts for a strong sustainability, several abstration levels and complex qualities of the natural systems enable us to start building an ample and fragmentary framework for designing bio-inspired and sustainable artefacts. The contributions hereby collected, will be used for mapping and selecting bio-inspired and sustainable case studies. As a consequence, the building of this methodological and operative framework, as a tool for sustainable design, that highlights the virtuous relationship of sustainable design and biomimetics, is not a definitive analysis; it is, rather, an open tool that only future planning trials will better clarify in detail.

\section{References}

[1] Manzini, E., Jégou, F., Quotidiano sostenibile. Scenari di vita urbana, Edizione Ambiente: Milano, pp. 45-55, 2003.

[2] Benyus, J. M., Biomimicry: Innovation Inspired by Nature, Harper Perennial: New York, USA, 2002.

[3] McDonough, W., Braungart, M., Cradle to Cradle, North Point Press, New York, 2002, (trad. it. di Elisa Banfi, Dalla Culla alla Culla, Blu edizioni, Torino, pp. 58-68 2003).

[4] Pauli, G., The Blue Economy: 10 Years, 100 Innovations, 100 Million Jobs. Report to the Club of Rome, Paradigm Publications, 2010. (trad.it. di Franco Lombini et al. The Blue Economy: 10 anni, 100 Innovazioni, 100 Millioni di lavori. Nuovo rapporto al Club di Roma, Edizione Ambiente: Milano, pp. 14-26, 2010). 
[5] Hawken, P., Lovins, A., Lovins, H., Capitalismo Naturale. La prossima rivoluzione industriale, Edizione Ambiente: Milano, 2001.

[6] Papanek, V., Progettare per il mondo reale, Mondadori: Milano, 1973.

[7] Salvia G., Rognoli V. e Levi M. , Il Progetto della Natura. Gli strumenti della biomimesi per il design, Franco Angeli: Milano, pp. 1-8, 2009.

[8] Langella, C., Hybrid design. Progettare tra tecnologia e natura. Franco Angeli: Milano, pp. 51-106, 2007.

[9] Kelly K., Out of Control. La nuova biologia delle macchine, dei sistemi sociali e dell'economia globale, Apogeo, Milano, pp. 1- 4, 1996.

[10] Vezzoli, C., Manzini, E., Design per la sostenibilità ambientale, Zanichelli: Bologna, pp. 11-18, 2007.

[11] Enciclopedia delle Scienze Garzanti, Garzantini editore s.p.a, pp. 27-28, 2005.

[12] Langella, C., Strategie biologiche a servizio del design. Online. www.digicult.it.

[13] Ranzo, P., La dimensione ibrida, scienza\&filosofia S\&F, pp. 46-49, 2011. Online. www.scienzaefilosofia.it.

[14] Vincent, J., Bogatyreva, O., Bogatyrev, N., Bowyer, A., Pahl, A. Biomimetics: its practice and theory, Journal of Royal Society Interface, 3(9), p. 471-482, 2006.

[15] Steadman, P., L'evoluzione del design. L'analisi biologica in architettura e nelle arti applicate, Liguori editore: Napoli, pp. 135, 1988.

[16] Montana, C. M., BIO-ID4S: Biomimicry in Industrial Design for Sustainability. An Integrated Teaching-and-Learning Method, VDM Verlag Dr. Muller Gmbh \& co. KG, Germany, pp. 165, 2010.

[17] Pietroni, L., Eco-materiali ed Eco-prodotti “Made in Italy”. Casi studio di eco-innovazione nelle imprese italiane, edizioni Kappa: Roma, pp. 26, 2004.

[18] Vezzoli, C., Manzini, E., Design per la sostenibilità ambientale, Zanichelli: Bologna, pp. 11, 2007.

[19] Gunter, P., Svolte Epocali. Il business per un futuro migliore, Baldini \& Castoldi: Milano, 1997.

[20] Reed B., Shifting from 'sustainability' to regeneration, Building Research \& Information, 35(6), pp. 674-680, 2007.

[21] Thackara J., From doomsday machine to clean growth economy, Conferenza "Sustain/ability festival", Treviso Design per un futuro sostenibile, Treviso, 2-4 dicembre 2010.

[22] Segrè, A., Lezioni di eco-stile, consumare, crescere, vivere, Bruno Mondadori, pp. 124-128, 2010.

[23] Lyle, J. T., Regenerative Design for Sustainable Development Winner, Merit Award for Communications, American Society of Landscape Architects, pp. 331-340, 1994.

[24] Pietroni, L., Il contributo della Biomimesi per un design sostenibile, bioispirato e rigenerativo, Op.cit. n. 141, Electa Napoli, Ivi, maggio 2011.

[25] Ferrara, M., Lucibello, S., Design follows Materials, Alinea Editrice: Firenze, pp. 21-39, 2009. 
[26] Wolfgang, S., Quotidiano sostenibile, scenari di vita urbana. Un equo benessere: otto cambiamenti verso una economia leggera, Wuppertal Institut, Edizione Ambiente: Milano, pp. 41-44, 2003.

[27] Design Council, Annual Review 2002, Fernedge: Londra, pp. 19, 2002.

[28] Thackara, J., In the bubble: Design per un futuro sostenibile, Umberto Allemandi \& C.: Torino, pp. 11, 2008.

[29] Faludi, J., Biomimicry For Green Design (A How-To), Online. http://www.worldchanging.com/archives/003680.html.

[30] Maturana H.R., Varela F.J., Autopoiesi e cognizione. La realizzazione del vivente, Marsilio: Venezia, p.110, 1985. 